\title{
Mechanisms and Empirical Modeling of Evaporation from Hardened Surfaces in Urban Areas
}

\author{
Jinjun Zhou ${ }^{1,2} \mathbb{D}_{\text {, Jiahong Liu }}^{1,3, * \mathbb{D}}$, Qi Chu ${ }^{1}$, Hao Wang ${ }^{1}$, Weiwei Shao ${ }^{3} \mathbb{D}_{\text {, Zhuoran Luo }}{ }^{1}$ \\ and Yongxiang Zhang ${ }^{1, *}$
}

1 Faculty of Architecture, Civil and Transportation Engineering, Beijing University of Technology, Beijing 100124, China; zhoujj@bjut.edu.cn (J.Z.); chuqi@bjut.edu.cn (Q.C.); wanghao123612@163.com (H.W.); 15611708278@163.com (Z.L.)

2 State Key Lab of Hydro-Science and Engineering, Tsinghua University, Beijing 100084, China

3 China Institute of Water Resources and Hydropower Research State Key Laboratory of Simulation and Regulation of Water Cycle in River Basin, Beijing 100038, China; shaoww@iwhr.com

* Correspondence: liujh@iwhr.com (J.L.); yxzhang@bjut.edu.cn (Y.Z.); Tel.: +86-10-6878-1936 (J.L.)

Citation: Zhou, J.; Liu, J.; Chu, Q.; Wang, H.; Shao, W.; Luo, Z.; Zhang, Y. Mechanisms and Empirical Modeling of Evaporation from Hardened Surfaces in Urban Areas. Int. J. Environ. Res. Public Health 2021, 18, 1790. https://doi.org/10.3390/ ijerph18041790

Academic Editor: Paul B. Tchounwou

Received: 3 January 2021

Accepted: 7 February 2021

Published: 12 February 2021

Publisher's Note: MDPI stays neutral with regard to jurisdictional claims in published maps and institutional affiliations.

Copyright: (c) 2021 by the authors. Licensee MDPI, Basel, Switzerland. This article is an open access article distributed under the terms and conditions of the Creative Commons Attribution (CC BY) license (https:/ / creativecommons.org/licenses/by/ $4.0 /)$.

\begin{abstract}
Urban evaporation, as an essential part of local water vapor resources in urban areas, has often been underestimated. One possible reason is that the evaporation of urban hardened surfaces is seldom considered and poorly understood in urban evaporation estimation. This study focused on the mechanisms and calculation of evaporation on hardened surfaces in urban areas. Experimental monitoring was used to monitor the processes and characteristics of evaporation on hardened surfaces. Mathematical models based on water quantity constraints were built to calculate evaporation of hardened surfaces. The results showed that: The interception abilities for rainwater and rainfall days of impervious hardened surfaces determine their evaporated water amount, which means no water, no evaporation for the impervious surfaces. The greater evaporation of artificial sprinkling on roads happened in fewer days of rainfall and frost. The evaporation of pervious hardened ground is continuous compared to the impervious surface. Its soil moisture in the sub-layer of permeable concrete decreases periodically with a period of one day. The evaporation of hardened surfaces occupies $16-29 \%$ of the total amount of evaporation in the built-up areas in cities. Therefore, the hardened surface evaporation has great significance on the urban hydrological cycle and urban water balance.
\end{abstract}

Keywords: urban hydrology; evaporation; hardened surfaces; urban environment; urban thermal comfort

\section{Introduction}

Urbanization has led to the expansion of urban population and urban hardened surface area [1,2]. Hardened surfaces refer to the artificial ground or roof structure which are paved with stone, brick, concrete, asphalt and so on. Typical hardened surfaces include asphalt road, cement ground, brick pavement, and building roof, which are the main underlying surfaces in cities. By the end of 2019, the proportion of urban population and hardened surfaces in cities were both above $60 \%$ in China [3]. Urban hardened surfaces bring great changes to the urban environment and hydrological process $[1,4,5]$. The usual results show that the increase of hardened surfaces in cities will reduce the evaporation, increase the sensible heat, increase the surface temperature, and aggravate the effect of urban heat island [6-8]. Therefore, the urban hardened surface will change the urban thermal comfort and influence public health $[9,10]$.

Evaporation is one of the main hydrological cycle processes [11,12], and it is also the main way to reduce urban sensible heat and alleviate the urban heat island effect [13]. Urban evaporation refers to the phenomenon of water transformation from liquid to gaseous state in urban areas. Similarly, the evaporation of hardened surfaces refers to the 
evaporation of water on or under the hardened ground structure. As the main underlying surface in cities, evaporation from hardened surfaces should be an important part of urban evaporation $[5,7,14]$. Observational data and the Princeton urban canopy model showed that evaporative fluxes from concrete pavements, building rooftops, and asphalt surfaces have a significant impact on the urban surface energy balance [15].

However, the research on evaporation of hardened surfaces is relatively weak, which may be due to two aspects: the monitoring of surface evaporation is difficult and the heterogeneity of hardened surfaces is high $[16,17]$. Hardened surfaces can be divided into impervious surfaces and pervious surfaces $[14,15]$. The impervious surface blocks water infiltration and reduces the water availability to be stored in the soil [18]. The water-storage capacity and the maximal wet surface fraction constitute the evaporation area of impervious surfaces [19]. For municipal roads in urban areas, water on roads comes from natural rainfall and artificial sprinkling [17]. Furthermore, the evaporation on the imperious surfaces occurs after rain or after artificial sprinkling [16,20-22] and plays a crucial role in road surface temperature simulations on rainy days [23]. Pervious hardened surfaces are structures that connect the surface and underground soil, which mean the rain water can infiltrate into the underground soil and the soil moisture can evaporate into the air through the pervious structure [24]. Yet, the evaporation of hardened surfaces is usually underestimated or even ignored in urban evaporation calculation in existing studies [16,25]. Meanwhile, urban hardened surfaces and human activity altered the land surface radiation balance, energy balance, and water balance $[26,27]$. Moreover, many parameters used in calculation and simulation, such as the roughness length, albedo, permeability, were changed [23] Less research has been done to revise the parameters of traditional evapotranspiration in urban evaporation calculation. For much research, evaporation is considered to be energy-constrained, and most of the evaporation calculations are based on the energy equation. Meanwhile, few researchers gave a detailed analysis of the hydrological responses of the pervious hard ground [28].

This research mainly focuses on the experimental study of evaporation on impervious and pervious hardened surfaces. The prototype monitoring experiments of artificial sprinklers and natural rainfall were carried out on several impervious ground, pervious, and the natural rainfall monitoring experiments were carried out on the ground of permeable concrete samples. The experiments answer the questions (1) what are the mechanisms that control evaporation from impervious and pervious hardened surfaces, and (2) can evaporation from these surfaces be represented with simple mathematical models? The monitor data are used to validate the model.

\section{Materials and Methods}

Experimental monitoring was carried out for impervious surfaces and pervious hardened surfaces, respectively. The experiment on impervious surfaces is mainly to monitor the water holding depth of the road. Under actual circumstances, the road being uneven or road depression is a popular phenomenon, and the depression area will develop into depression storage after rainfall happens, which will increase the evaporation of the impervious surfaces. In this study, the authors assume that the pavement is flat and not depressed, and the influence of the depression of impervious surfaces is not considered.

For pervious hardened surfaces, the evaporation change should be monitored by measuring soil moisture content of both pervious hardened layer and subsoil layer, which the water can penetrate the pervious hardened structure and the water vapor of subsoil can pass the pervious structure into the air. The evaporation of pervious hardened surface will influence the temperature and humidity of the surface, and the rainfall will directly change the soil moisture in pervious hardened ground, so these elements are also monitored in this study. Soil moisture content is recorded by soil moisture probe, rainfall is recorded by rainfall barrel, RH and temperature are recorded by temperature and humidity selfrecording instrument. There are other meteorological factors that affect the evaporation 
process, such as wind speed, net radiation, and so on $[29,30]$. These meteorological data are derived from the monitoring data of the weather station.

\subsection{Experiment on Impervious Ground}

The experimental method of intercepting rain water depth is the determination of ground interception capacity under artificial sprinkling. First, the authors chose a piece of clean and flat impervious hardened ground as the monitoring object, and then lay a rectangular plexiglass bottomless tank to adjust the position to ensure that there is no obvious gap between the sides and the ground. Then, they sprinkled the water evenly in the tank with a sprayer until the runoff occurs at a certain point to stop sprinkling water. To measure weight difference of the spray before and after spraying by weighing, which is the amount of water sprayed, the depth of the impervious ground interception rain water is recorded as $H$ and the unit is $\mathrm{mm}$. The $H$ measured by the above method is calculated as:

$$
H=\frac{m}{1000 \times A}
$$

where, $m$ is the amount of sprinkling water at critical runoff in the rainfall area, the unit is $\mathrm{g}$; $A$ is the rainfall area of model experiment, the unit is $\mathrm{m}^{2}$.

In this study, the size of the tank is $0.5 \mathrm{~m} \times 0.5 \mathrm{~m}$, and the $A$ is $0.25 \mathrm{~m}^{2}$. The precision of experimental electronic weighing is $1 \mathrm{~g}$ and the maximum range is $5 \mathrm{~kg}$. The precision is $0.004 \mathrm{~mm}$ in this experiment area, which meets the precision requirement of experimental result $0.01 \mathrm{~mm}$. The most commonly used asphalt pavement, cement pavement, concrete pavement and brick pavement are selected as the experimental monitoring objects of impervious hardened surfaces. Three types of brick pavement were selected for the experiment, and their gap ratios were $2 \%, 4 \%$, and $6 \%$. Gap ratio is the value of gap area dividing total area in a certain brick pavement area, the bricks sealed with concrete or mortar between them. The number of sprinkling experiments on the same ground is not less than 10.

\subsection{Experiment on Pervious Hardened Ground}

In this study, two organic glass water tanks of $0.5 \mathrm{~m} \times 0.5 \mathrm{~m}$ were made. According to the standard atlas of "Urban Road-pervious sidewalk laying" (16MR2004), the experimental model of permeable concrete road was set up, which was installed by professional engineers. $\mathrm{HOBO}$ series products were used to monitor and collect soil moisture, concrete moisture and soil temperature data, including the data acquisition unit (HOHO H21-USB), soil moisture probe (S-SMC-M005), and soil temperature probe (HOBO S-TMB-MOO6). For the S-SMC-M005, the volumetric water content range is $0 \sim 0.55 \mathrm{~m}^{3} / \mathrm{m}^{3}$, the precision range is $\pm 3.1 \%$, the resolution is $0.0007 \mathrm{~m}^{3} / \mathrm{m}^{3}(0.07 \%)$, and the effective soil volume is $0.3 \mathrm{~L}$. The range of HOBO S-TMB-MOO6 is $-40 \sim 100{ }^{\circ} \mathrm{C}$, the precision is $\pm 0.2^{\circ} \mathrm{C}\left(0 \sim 50{ }^{\circ} \mathrm{C}\right)$, the resolution is $0.03{ }^{\circ} \mathrm{C}$, the response time is $<30 \mathrm{~s}(90 \%$, in flowing water), and $<3 \mathrm{~min}$ $(90 \%, 1 \mathrm{~m} / \mathrm{s}$ in air). The above technical parameters meet the experimental conditions and requirements of this study. The soil moisture monitor plan was shown in Figure 1. The thickness of the permeable concrete structure layer is $150 \mathrm{~mm}$, and the thickness of the lower soil is $200 \mathrm{~mm}$ in the experimental group. The soil depth is $350 \mathrm{~mm}$ in the control group. The monitoring probe is placed in the middle of the structure layer, so the placement depth of the probes from top to bottom are $75 \mathrm{~mm}$ and $250 \mathrm{~mm}$, respectively.

The change of surface temperature and RH (relative humidity) is recorded by temperature and humidity loggers (WSZY-1) on the surface of concrete. The temperature measurement range is from $-40 \sim 100{ }^{\circ} \mathrm{C}$ with an uncertainty below $\pm 0.5^{\circ} \mathrm{C}$ and resolution of $0.1{ }^{\circ} \mathrm{C}$, while the $\mathrm{RH}$ measurement range is $0 \sim 100 \%$ with an uncertainty less than $\pm 3 \%$ and resolution of $0.1 \% \mathrm{RH}$ [31]. In order to avoid the effect of light on permeable concrete and soil evaporation, orange wallpaper was pasted on the water tank wall to shade the light. The site of the experiment is the open-air platform on the fourth floor of the new water conservancy building of Tsinghua University. Two kinds of control conditions were 
set up in the experiment, one was bare soil surface and the other was natural vegetation surface, and the experimental arrangement was shown in Figure 2. The experimental time of bare soil surface control was 8 May-13 June 2018, and that of natural plant control was from 14 June to 14 July 2018.

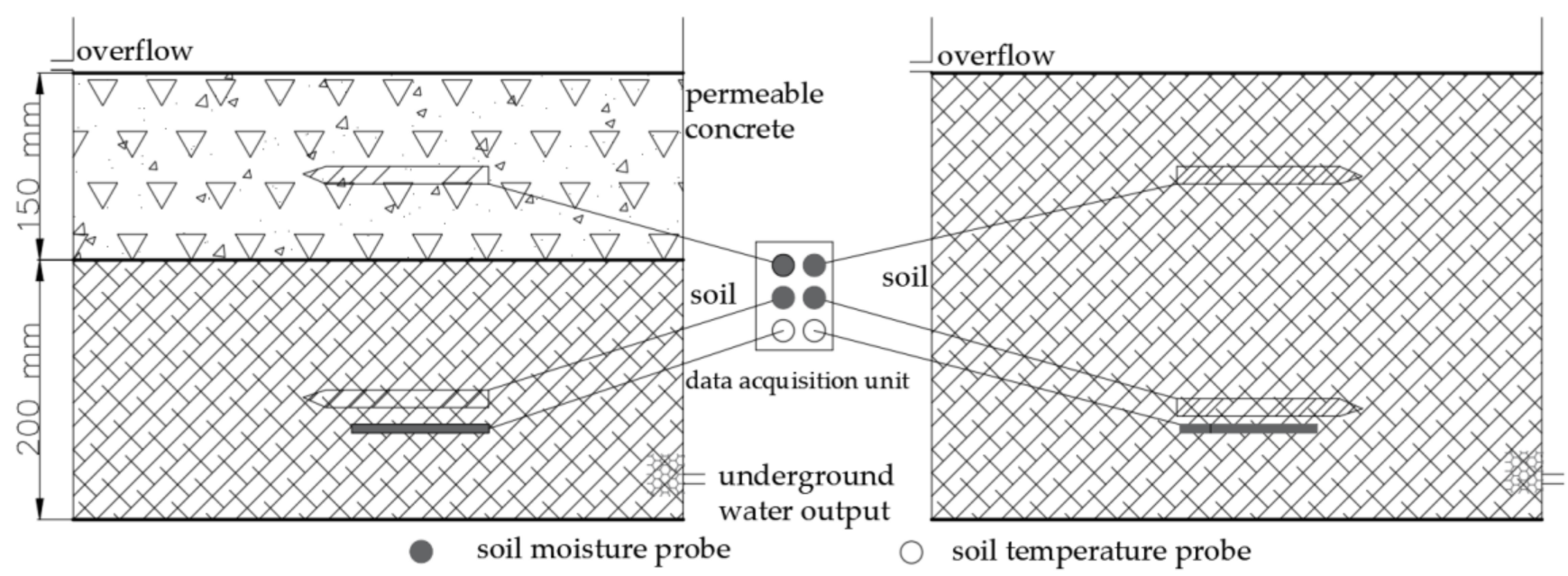

Figure 1. Experimental monitor plan for permeable concrete pavement.

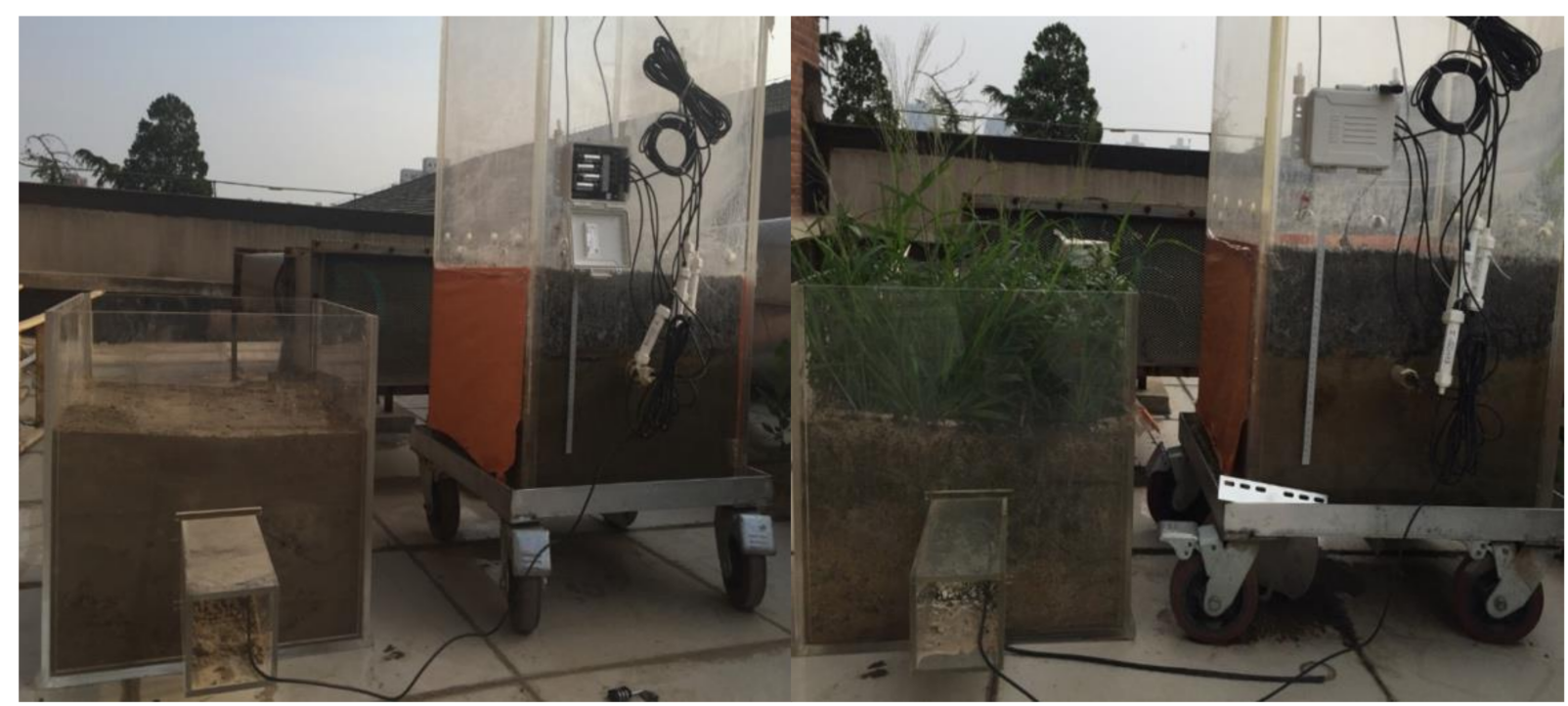

(a)

(b)

Figure 2. Experimental layout of permeable concrete pavement: (a) control group of bare soil; (b) control group of nature vegetation.

\subsection{Calculation Model}

The intercepted rain water is the main source of evaporation on the impervious hardened surfaces. If the maximum water holding depth of the impervious surface is recorded as $H$, when the sum of rainfall depth $(P)$ and current water depth $(S)$ is less than $H$, the actual evaporation amount $\left(E_{i}\right)$ is equal to the sum of rainfall and current water quantity $(P+S)$. Conversely, evaporation is equal to the maximum water holding depth $H$. This relationship is expressed in Equation (2).

$$
\left.\begin{array}{r}
P+S<H, E_{i}=P+S \\
P+S \geq H, E_{i}=H
\end{array}\right\}
$$


On an annual scale, evaporation from impervious ground is equal to accumulated rainfall interception. There is an initial loss value $\left(H_{0}\right)$ for daily rainfall, when the rainfall is less than this value, the rainfall evaporates completely, and when the rainfall is greater than this value, the daily evaporation force is equal to this value $\left(H_{0}\right)$

$$
E_{H}=P_{H}+H_{0} \times N_{H}
$$

where $E_{H}$ is the annual evaporation on the impervious surface, $P_{H}$ is the sum of the daily rainfall that less than $H_{0}, N_{H}$ is the number of days that daily rainfall was greater than $H_{0}$.

Road sprinkling is a common municipal public measure to reduce dust and improve the quality of urban environment. Since the road is impervious, all the water that is artificially sprinkled on the road evaporates into the air, so the evaporation of the artificial sprinkling can be calculated by statistical method.

$$
W_{A}=1000 \times H_{A} \times\left(365-d_{\text {frost }}-d_{\text {rain } 1}\right) \times A_{r}
$$

where $W_{A}$ is the total water content of artificial sprinkling on the imperious road, $\mathrm{m}^{3} ; H_{A}$ is the depth of artificial sprinkling water, $\mathrm{mm}$ (Combined with experimental results and investigation results, the $H_{A}=0.65 \mathrm{~mm}$ in this study); $d_{\text {frost }}$ is the number of frost days; $d_{\text {rain }}$ is the number of raining days; $A_{r}$ is the area of artificial sprinkler roads, $\mathrm{km}^{2}$. In this study, the days number of one year is 365 .

Where $E_{A}$ is the evaporation intensity of artificial sprinkling on the built-up areas, $\mathrm{mm} ; A_{I H}$ is the area of imperious hardened surface in cities, $\mathrm{km}^{2}$.

$$
E_{A}=\frac{W_{A}}{1000 \times A_{I H}}
$$

Pervious hardened surfaces can penetrate rain water through structural pores and store water in these pores. Their pore structure can connect the lower soil and the upper air and keep the continuous evaporation of the lower soil during the non-rainfall period. The actual water holding capacity is marked as $S_{a}$, the rainfall intensity is marked as $p$, the permeability of the pervious layer is recorded as $k$, the water holding capacity of the pervious layer is $S_{c}$, the initial water content is $S_{0}, t$ is the duration of rainfall, the rainfall is $P$, and $R$ is the runoff on the pervious hardened surface. The relationships between these variables are expressed as follows under different rainfall intensity and rainfall amount.

$$
\left.\begin{array}{c}
\text { if } p<k, P<S_{c}-S_{0} \text {, then } S_{a}=S_{0}+P \\
\text { if } p<k, P>S_{c}-S_{0} \text {, then } S_{a}=S_{c}, R=P-S_{c} \\
\text { if } p>k, P>S_{c}-S_{0} \text {, then } S_{a}=S_{c}, R=P-S_{c} \\
\text { if } p>k, P<S_{c}-S_{0} \text {, then } S_{a}=S_{0}+k t, R=(p-k) t
\end{array}\right\}
$$

\section{Results}

The monitoring results of typical impervious surfaces interception were shown in Figure 3 through the histogram. According to the experimental monitoring results, the water holding depths of brick, asphalt, cement, and concrete ground were distributed between $0.4-1 \mathrm{~mm}$, and the average value is nearly $0.56 \mathrm{~mm}$, which was close to the depth of artificial sprinkling on roads. The depth of water interception of asphalt pavement was greater than that of other types of impervious pavement. The water holding depth of concrete pavement was slightly higher than that of cement pavement. These differences were mainly due to the different roughness of impervious surfaces with different materials. Without considering the water absorption performance of the material, the ground surface with large roughness has strong intercepting rain water ability, and also has large evaporating strength. For brick pavements, the greater water interception depth happened on the larger gap ratio pavements, because the gap had a certain groove depth and water retention capacity. 
Based on formula (4) and measured rainfall data in 2015 (Table 1), the evaporation intensity of impervious surfaces in 31 provincial capital cities in China was calculated. Due to the lack of measured meteorological data, there was no calculation of hardened surfaces evaporation in the three cities of Taipei, Macao and Hong Kong. Figure 4 showed the intensity of the evaporation of rainwater intercepted by the impervious surfaces in capital cities in 2015. Based on the experimental data and referring to the recommended value of "Technical Guide for Sponge City Construction in China", The initial loss value was $2 \mathrm{~mm}$ when it was upscaled to regional or larger scales $\left(H_{0}=2\right)$ in this study.

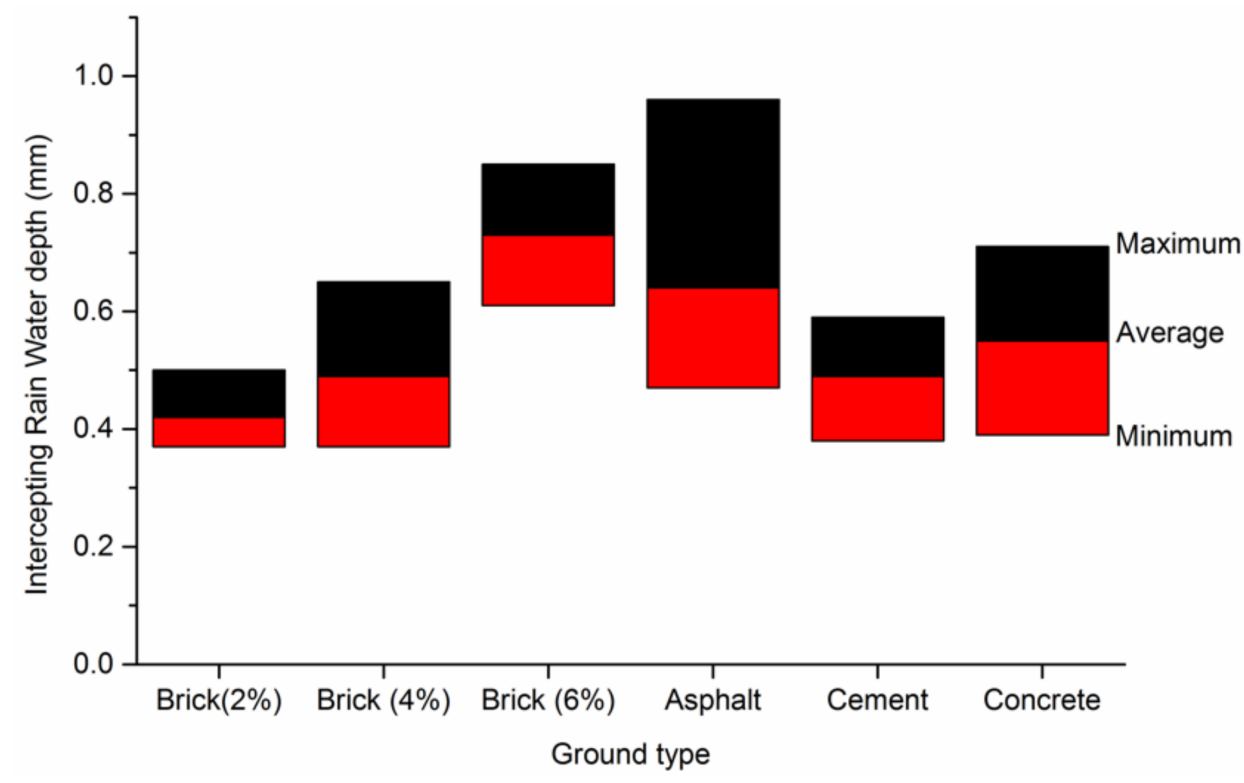

Figure 3. Experimental results of typical impervious surfaces interception.

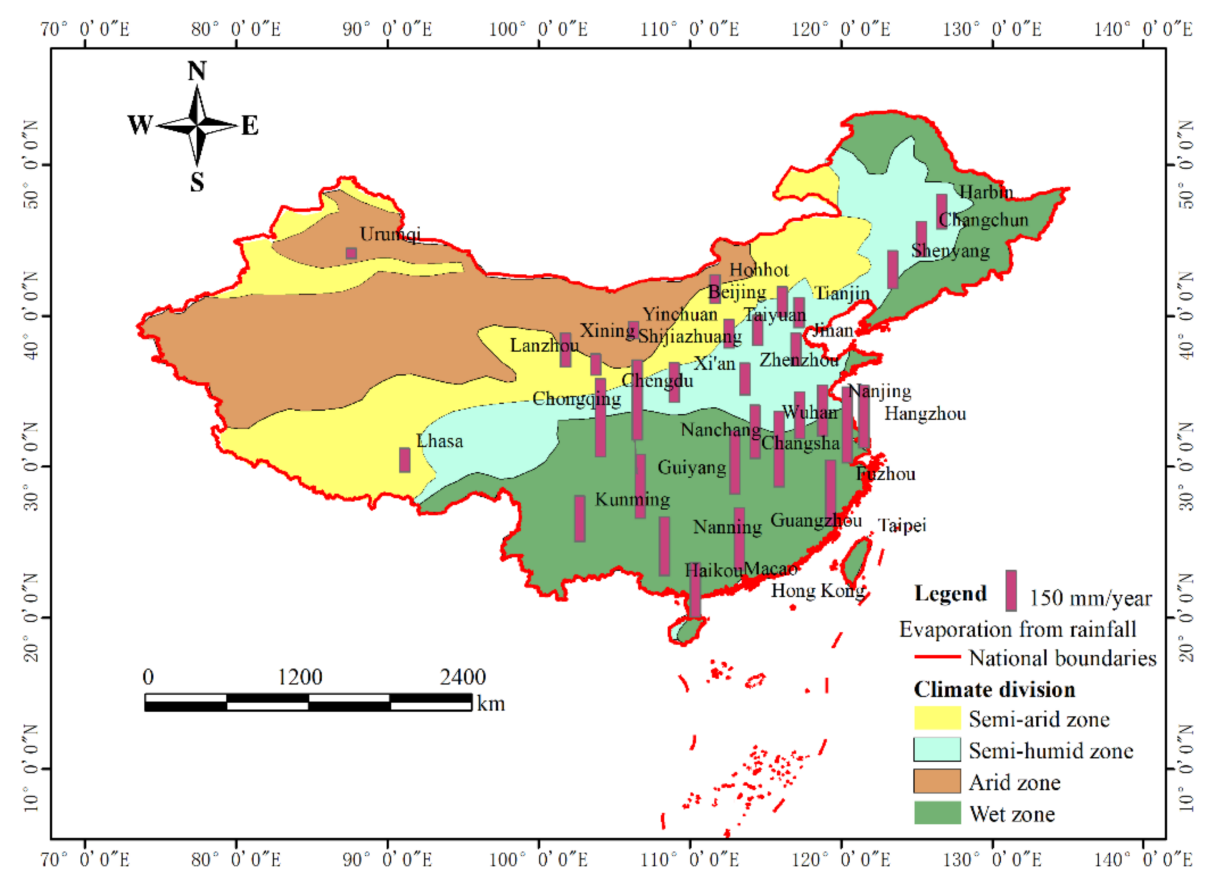

Figure 4. Evaporation intensity of impervious surfaces from rainfall in provincial capital cities in China in 2015.

The land in China is divided into four geographical regions according to annual rainfall: humid region (annual rainfall is more than $800 \mathrm{~mm}$ ), semi-humid region (annual 
rainfall is between $400-800 \mathrm{~mm}$ ), semi-arid region (annual rainfall is between $200-400 \mathrm{~mm}$ ), and arid region (annual rainfall is less than $200 \mathrm{~mm}$ ) [32]. The evaporation intensity of impervious surfaces in cities in humid areas was much higher than that in arid and semiarid areas. The smallest evaporation intensity city in 2015 was Urumqi, with only $37.3 \mathrm{~mm}$, and the largest value was $298 \mathrm{~mm}$, which happened in Chengdu. The results showed that more than half of the cities have evaporation intensity from rainfall on impervious surfaces above $150 \mathrm{~mm}$ in one year, and these cities were mainly distributed in wet areas.

Table 1. Rainfall related data in 31 provincial capitals of China in 2015.

\begin{tabular}{|c|c|c|c|c|c|}
\hline Cities & $\begin{array}{l}\text { Rainfall in } \\
2015 \text { (mm) }\end{array}$ & $d_{\text {rain }}(\mathrm{d})$ & $N_{H}(\mathrm{~d})$ & $d_{\text {frost }}(\mathrm{d})$ & $\begin{array}{c}\text { Impervious } \\
\text { Area Rate (\%) }\end{array}$ \\
\hline Beijing & 458.6 & 77 & 45 & 5 & $54.21 \%$ \\
\hline Tianjin & 574.2 & 79 & 44 & 5 & $67.92 \%$ \\
\hline Shijiazhuang & 481.4 & 74 & 44 & 4 & $59.81 \%$ \\
\hline Taiyuan & 403.6 & 79 & 35 & 2 & $63.93 \%$ \\
\hline Hohhot & 361.9 & 77 & 38 & 94 & $66.00 \%$ \\
\hline Shenyang & 573.2 & 93 & 56 & 89 & $61.67 \%$ \\
\hline Changchun & 530.5 & 99 & 50 & 117 & $65.88 \%$ \\
\hline Harbin & 420.1 & 105 & 49 & 126 & $67.19 \%$ \\
\hline Shanghai & 1648.8 & 152 & 96 & 0 & $66.00 \%$ \\
\hline Nanjing & 1765.6 & 124 & 75 & 0 & $60.53 \%$ \\
\hline Hangzhou & 2131.9 & 169 & 121 & 0 & $62.56 \%$ \\
\hline Hefei & 1258.2 & 128 & 72 & 0 & $61.75 \%$ \\
\hline Fuzhou & 1778.2 & 166 & 98 & 0 & $59.92 \%$ \\
\hline Nanchang & 2204.7 & 173 & 115 & 0 & $61.10 \%$ \\
\hline Jinan & 713.8 & 75 & 54 & 3 & $65.00 \%$ \\
\hline Zhengzhou & 689.1 & 86 & 46 & 1 & $64.68 \%$ \\
\hline Wuhan & 1432.8 & 138 & 79 & 0 & $65.81 \%$ \\
\hline Changsha & 1538.3 & 162 & 100 & 0 & $66.10 \%$ \\
\hline Guangzhou & 2471.9 & 248 & 101 & 0 & $63.94 \%$ \\
\hline Nanning & 1222.3 & 156 & 85 & 0 & $63.02 \%$ \\
\hline Haikou & 1673.2 & 135 & 84 & 0 & $61.90 \%$ \\
\hline Chongqing & 1416.7 & 122 & 84 & 0 & $62.62 \%$ \\
\hline Chengdu & 1388.6 & 211 & 112 & 0 & $64.43 \%$ \\
\hline Guiyang & 1430.8 & 193 & 83 & 0 & $62.83 \%$ \\
\hline Kunming & 1216.1 & 122 & 69 & 0 & $62.75 \%$ \\
\hline Lhasa & 326.1 & 64 & 32 & 2 & $64.02 \%$ \\
\hline Xi'an & 578.9 & 103 & 53 & 0 & $65.72 \%$ \\
\hline Lanzhou & 266.7 & 60 & 25 & 4 & $75.86 \%$ \\
\hline Xining & 306.2 & 111 & 43 & 15 & $62.53 \%$ \\
\hline Yinchuan & 227.1 & 53 & 21 & 15 & $59.10 \%$ \\
\hline Urumqi & 105.7 & 33 & 12 & 96 & $63.00 \%$ \\
\hline
\end{tabular}

According to formula (4) and (5) and rainfall data in Table 1, the evaporation intensity from artificial sprinkling on imperious hardened surfaces of each capital city in 2015 was calculated, and the results were shown in Figure 5. The results showed that more than half of the cities have evaporation intensity from artificial sprinklers on impervious surfaces above $27 \mathrm{~mm}$ in one year. These cities were mainly distributed in arid and semi-arid areas. Other cities with relatively low levels of evaporation intensity from artificial sprinkling on impervious ground include four cities in northern China and several cities in wet areas with adequate rainfall. Compared with the evaporation intensity from the rainfall interception, the intensity distribution of artificial sprinkling on impervious surfaces in provincial capital cities were relatively uniform.

Total evaporation from impervious surfaces equals the sum of evaporation from rainfall and from artificial sprinkling. In order to analyze the total evaporation intensity of impervious surfaces on the urban built-up areas, the total water volume of evaporation on hardened surfaces from rainfall and artificial sprinklers was evenly distributed on the urban built-up area in each city. The evaporation intensity of the urban impervious 
surfaces on built-up areas was calculated, and the results were shown in Figure 6. The results showed that interception of rainwater on impervious surfaces accounted for more than $70 \%$ of total evaporation from impervious surfaces.

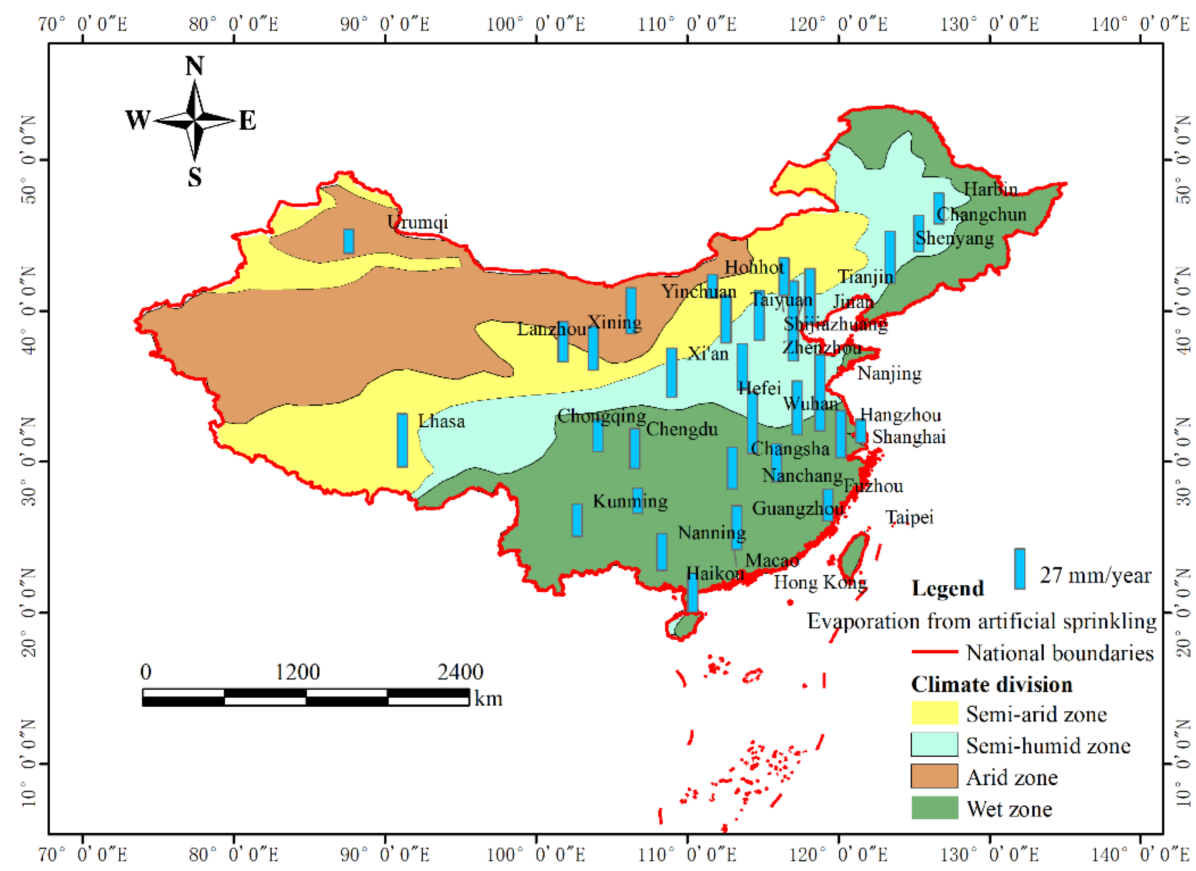

Figure 5. Evaporation intensity of impervious surfaces from artificial sprinkling on built-up areas in provincial capital cities in China in 2015.

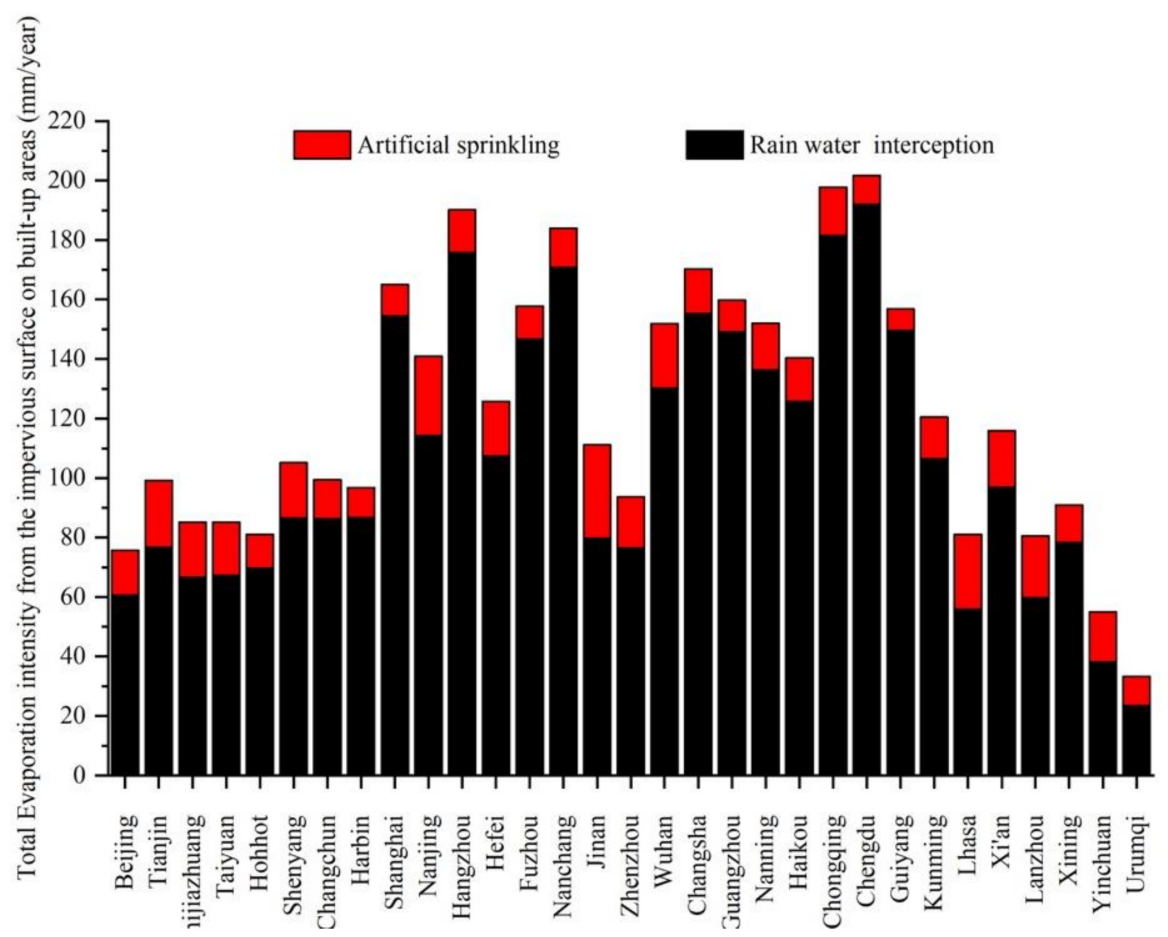

Figure 6. Total evaporation intensity from the impervious hardened surfaces on the built-up area in each capital city.

Figure 7 showed the monitoring results of soil moisture change of the experimental group (permeable concrete pavement) and control group (bare soil surface). The experimental monitoring time was 9-15 May 2018. During this period, the control group was 
subjected to two artificial precipitations, which were 11 May and 13 May, respectively. The experimental group was carried out an artificial precipitation on May 13. This artificial precipitation caused water to accumulate on the surface of the permeable concrete, that is, the water in the permeable concrete layer was saturated on 13 May. Water content of soil under concrete layer and bare soil layer and water content of permeable concrete layer were also measured. When precipitation occurs, the values of three monitored soil moisture were rising rapidly. The water content in the permeable concrete layer rose from the afternoon to the maximum water content, and continued to fall after midnight, thus repeatedly showing periodic change. The soil water content under the permeable concrete and the soil water content in the bare soil showed fluctuations during the non-rainfall period. The fluctuations were reflected in the daily change process, which means, starting to rise every morning, reaching the peak around 3 p.m. Its rise time was ahead of the rise time in permeable concrete. The relative humidity (RH) of the concrete layer surface also changed periodically, but its peak lagged behind the peak of soil moisture in the concrete layer. The temperature in the surface of the concrete layer and the soil in the lower layer also showed periodic changes. The peak of the surface temperature appeared at 12:00 a.m., and the peak of the lower soil temperature appeared at 0:00 a.m.

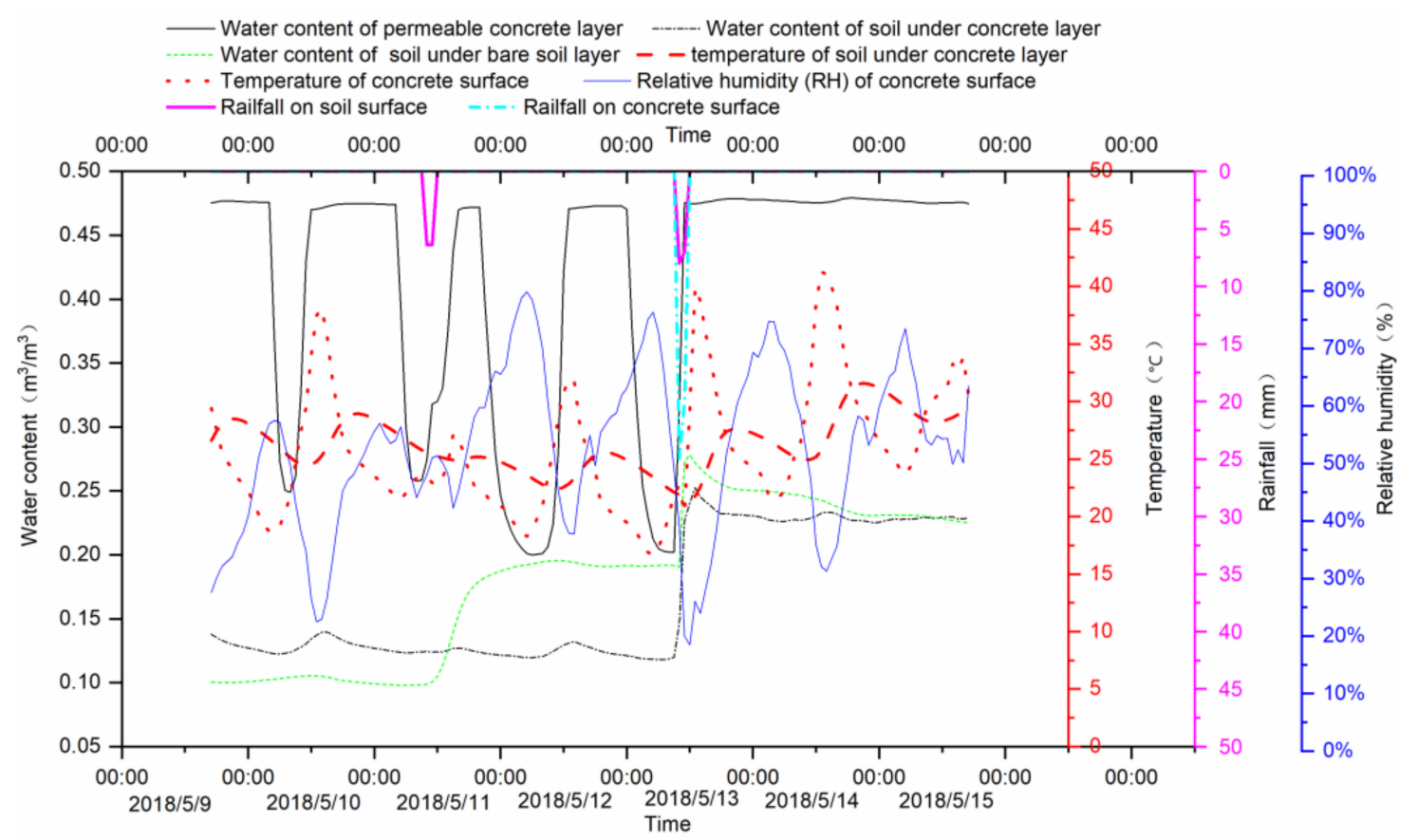

Figure 7. Monitoring results of permeable concrete pavement in the comparison of bare soil surface.

The Figure 8 showed the monitoring results in the comparison of native vegetation surface. The vegetation was setaria viridis, which was naturally grown vegetation in this study (Figure $2 \mathrm{~b}$ ). The monitoring time was between 26 June and 3 July, and a natural rainfall occurred. When rainfall occurred on $1 \mathrm{July}$, the moisture content of the permeable concrete and the underlying soil rose rapidly and visibly, but the soil moisture under the natural vegetation layer changed by a smaller magnitude. The results showed that the soil moisture in the lower layer of natural vegetation was decreasing smoothly, while the soil moisture in the permeable concrete had diurnal fluctuations. Water content of permeable concrete layer was showing periodic changes during non-rainfall periods, and the trough was gradually declining. The water content of the concrete layer had been in the peak for a few days after the rain. The $\mathrm{RH}$ of the concrete surface reached peak during natural rainfall, and the value nearly approached $100 \%$. The temperature change characteristics of the concrete surface and under soil layer were the same as in Figure 7. 


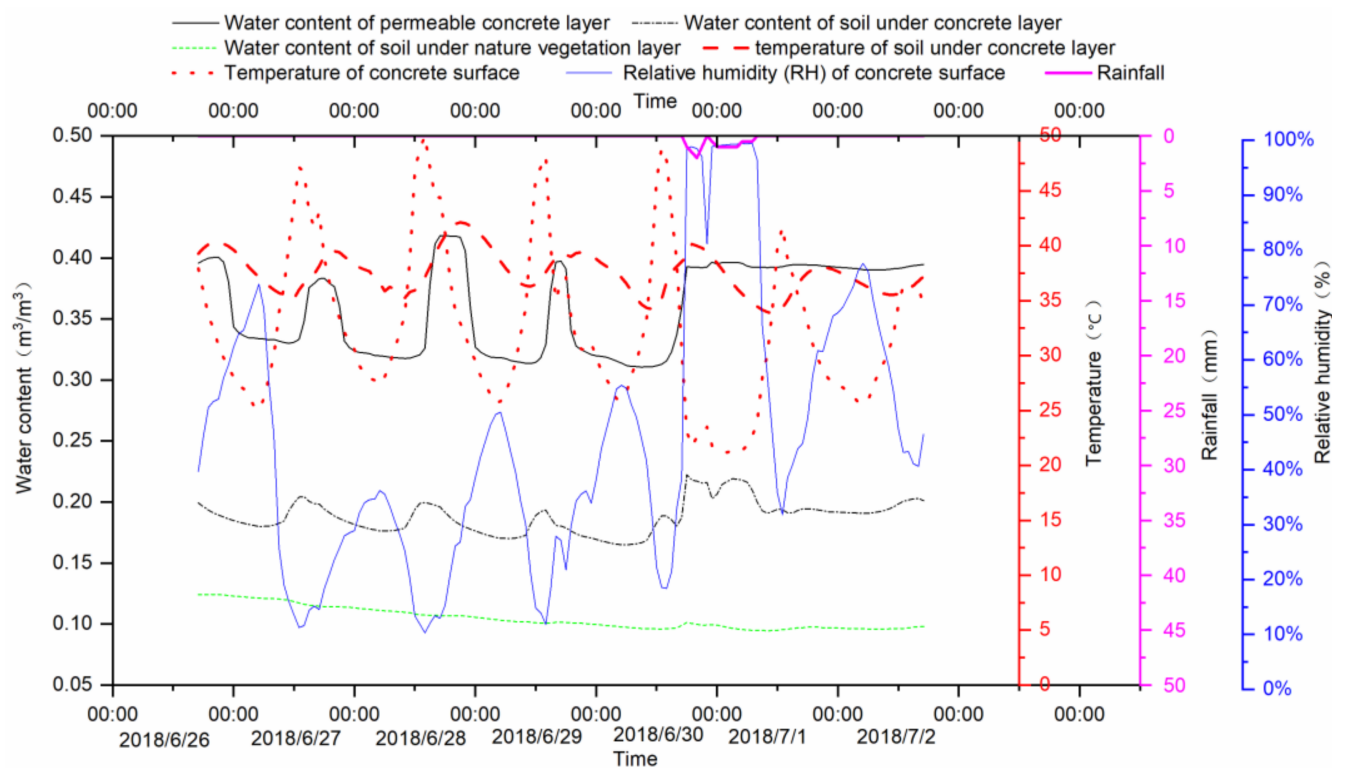

Figure 8. Monitoring results of permeable concrete pavement in the comparison of native vegetation surface.

\section{Discussion}

The evaporation of impervious hardened surfaces comes from the interception of rain water and artificial sprinkling (suitable for some roads with artificial sprinkling) on the surface. The rainwater interception capacity of impervious surfaces primarily determines the magnitude of surface evaporation. The data are the reference basis for artificial sprinkling on city roads, and this is also the base to calculate the evaporation from artificial sprinkling on the impervious road. Due to limited water storage capacity of impervious surfaces, the evaporation of impervious surfaces is a water-constrained type of evaporation, and further results showed that the number of days of rainfall is the key factor affecting annual evaporation. According to the annual evaporation results in Figure 4, the larger evaporation happened in cities with more days of rainfall, which are usually distributed in wet areas.

Unlike the evaporation of natural rainfall, the larger evaporation of hardened surfaces caused by artificial sprinklers happened in cities with less rainfall days and frost days. In mid-latitude cities with less rainfall, such as Beijing, Tianjin, Taiyuan, Shijiazhuang, Jinan and Zhengzhou, the evaporation from artificial sprinklers is higher than other cities, because they are located in relatively arid areas, with fewer frost days.

Further analysis in Figure 6 found that the evaporation on impervious surfaces from rainfall interception is 10-22 times that from artificial sprinkling in cities in humid areas, while this ratio interval is $3-10$ times in cities in arid and semi-arid areas. In order to analyze the effect of evaporation from impervious hardened surfaces on urban evaporation, five cities' urban evapotranspiration values were collected from the research literature. The five cities are Beijing, Shijiazhuang, Shanghai, Guangzhou and Chengdu. Their average annual urban evapotranspiration were $407 \mathrm{~mm}, 529 \mathrm{~mm}, 751 \mathrm{~mm}, 767 \mathrm{~mm}$, and $730 \mathrm{~mm}$, which were by traditional methods that ignored evaporation from the impervious surfaces. The proportion of impervious surfaces evaporation in traditional urban evapotranspiration is $18.34 \%$ in Beijing, $16.37 \%$ in Shijiazhuang, $21.97 \%$ in Shanghai, $21.90 \%$ in Guangzhou, and $28.68 \%$ in Chengdu, respectively.

From the monitoring results of Figures 7 and 8, the variation of water content in permeable concrete layers shows a fluctuating pattern. Without new rainfall, the value of the trough is gradually decreasing, indicating that evaporation is continuing to occur, and the period of wave crest and trough variation is one day. The reason for the fluctuating change is that the soil moisture in the lower layer evaporates through the monitoring point. Evaporation is affected by meteorological factors such as surface temperature, humidity, 
sensible heat and so on. These meteorological elements on the surface of permeable concrete fluctuate periodically in the results of experimental monitoring. This is also the reason for the periodic fluctuation of soil water evaporation in the sub-layer of permeable concrete.

In the control group of bare soil and natural vegetation, the change of soil moisture is close to smooth, which is different from the periodic fluctuation of the same depth in the experimental group. When high intensity heavy rain occurs, the increase of soil moisture in the lower layer of permeable concrete is lower than that in bare soil control scenario. However, when low intensity small rainfall occurs, the increase of soil moisture in the lower layer of permeable concrete is much higher than that in bare soil and natural vegetation conditions.

\section{Conclusions}

Urban hardened surfaces can be divided into impervious hardened surfaces and pervious hardened surfaces. Impervious hardened surfaces will intercept rain water, and this part rain water all evaporates into air. For some roads, there will be municipal artificial sprinkling, and this part of the water also contributes to urban evaporation. The evaporation of impervious hardened surfaces is water constrained evaporation, which means the evaporation happens only when there is water on the impervious surfaces, so this evaporation is intermittent. The annual evaporation of urban impervious surfaces from the interception of rain water is closely related to number of rainfall days. Based on the results of evaporation of hardened surfaces in 31 provincial capital cities in China in 2015, it can be concluded that the distribution intensity of evaporation of hardened surfaces in the built-up area is $40-210 \mathrm{~mm}$. The evaporation of impervious pervious hardened surfaces accounts for 16-29\% in the urban evapotranspiration calculated by the traditional methods in five capital cities, which is non-negligible part in the evaporation calculation in urban built-up areas.

Considering that the proportion of pervious hardened surfaces in urban areas is particularly small (negligible compared to impervious hardened surfaces) in China's cities in 2015, the evaporation of water-pervious hardened surfaces is not taken into account in this study. Through experimental monitoring, we compared the evaporation characteristics of subsoil in pervious hardened surfaces with the bare soil and natural vegetation surface. The results found that the pervious hardened surfaces can penetrate water and connect the lower soil to the surface atmosphere [33]. The evaporation of pervious hardened surfaces is continuous compared to impervious surfaces. The soil moisture in the sub-layer of permeable concrete decreases in a wave-like manner during the absence of rainfall, while the soil moisture under the layer of bare soil or natural vegetation decreases smoothly at the same depth.

The authors concluded that evaporation of the impervious hardened surfaces is intermittent, while evaporating evaporation of the pervious hardened surface is continuous. When there is water on impervious surfaces, the evaporation happens, otherwise there's no evaporation. For the pervious surfaces, the rainfall can seep, and water from the underlying soil can also pass through the hardened layer and evaporate into the air. The amount of evaporation of urban hardened surfaces occupies a certain proportion between 16-29\% of the total amount of evaporation in the built-up areas. The evaporation of hardened surfaces is also an important link of urban hydrological cycle and an important flux of urban water balance.

Author Contributions: Conceptualization, J.L. and Y.Z.; methodology, J.Z.; software, H.W.; validation, J.Z., Q.C. and W.S.; formal analysis, J.Z.; investigation, J.Z.; resources, J.Z.; data curation, Z.L.; writing-original draft preparation, J.Z., H.W. and Q.C.; writing-review and editing, J.Z.; visualization, W.S. and Z.L.; supervision, Y.Z.; project administration, J.L. and Y.Z.; funding acquisition, J.L. and J.Z. All authors have read and agreed to the published version of the manuscript.

Funding: This research was funded by the National Key Research and Development Program of China, grant number 2016YFC0401401; the Chinese National Natural Science Foundation, grant number 51739011 \& 51879274; the Beijing Municipal Natural Science Foundation, grant number 
8212042; the research fund of the China Postdoctoral Science Foundation Project, grant number 2019M660380; the research fund of Joint Open Research Fund Program of State key Laboratory of Hydroscience and Engineering and Tsinghua-Ningxia Yinchuan Joint Institute of Internet of Waters on Digital Water Governance, grant number sklhse-2021-Iow07, and the State Key Laboratory of Simulation and Regulation of Water Cycle in River Basin, grant number 2020ZY03.

Institutional Review Board Statement: The object of this study is urban hardened surface, and there are no experiments or related studies directly involving human bodies or animals, therefore, this study did not require ethical approval.

Informed Consent Statement: Not applicable.

Data Availability Statement: Data sharing not applicable.

Conflicts of Interest: The authors declare no conflict of interest.

\section{References}

1. Kalnay, E.; Cai, M. Impact of urbanization and land-use change on climate. Nature 2003, 423, 528-531. [CrossRef] [PubMed]

2. Yao, X.; Wang, Z.; Wang, H. Impact of Urbanization and Land-Use Change on Surface Climate in Middle and Lower Reaches of the Yangtze River, 1988-2008. Adv. Meteorol. 2015, 2015. [CrossRef]

3. Wang, H.; Wang, J.; Liu, J.; Mei, C. Analysis of urban water cycle evolution and countermeasures. J. Hydraul. Eng. 2020, 51, 1-10. [CrossRef]

4. Jeykumar, R.K.C.; Chandran, S. Impact of urbanization on climate change and geographical analysis of physical land use land cover variation using RS-GIS. Glob. Nest. J. 2019, 21, 141-152. [CrossRef]

5. Gao, X.; Guo, M.; Yang, Z.; Zhu, Q.; Xu, Z.; Gao, K. Temperature dependence of extreme precipitation over mainland China. J. Hydrol. 2020, 583. [CrossRef]

6. Ghatak, D.; Zaitchik, B.; Hain, C.; Anderson, M. The role of local heating in the 2015 Indian Heat Wave. Sci. Rep-UK 2017, 7. [CrossRef]

7. Drijfhout, S. The relation between natural variations in ocean heat uptake and global mean surface temperature anomalies in CMIP5. Sci. Rep-UK 2018, 8. [CrossRef] [PubMed]

8. Fitria, R.; Kim, D.; Baik, J.; Choi, M. Impact of Biophysical Mechanisms on Urban Heat Island Associated with Climate Variation and Urban Morphology. Sci. Rep-UK 2019, 9. [CrossRef] [PubMed]

9. Wang, L.; Chen, R.; Sun, W.; Yang, X.; Li, X. Impact of High-Density Urban Built Environment on Chronic Obstructive Pulmonary Disease: A Case Study of Jing'an District, Shanghai. Int. J. Env. Res. Pub. Health 2020, 17, 252. [CrossRef] [PubMed]

10. Grazuleviciene, R.; Vencloviene, J.; Kubilius, R.; Grizas, V.; Danileviciute, A.; Dedele, A.; Andrusaityte, S.; Vitkauskiene, A.; Steponaviciute, R.; Nieuwenhuijsen, M. Tracking Restoration of Park and Urban Street Settings in Coronary Artery Disease Patients. Int. J. Env. Res. Pub. Health 2016, 13, 550. [CrossRef]

11. Liu, W.; Hong, Y.; Khan, S.I.; Huang, M.; Vieux, B.; Caliskan, S.; Grout, T. Actual evapotranspiration estimation for different land use and land cover in urban regions using Landsat 5 data. J. Appl. Remote Sens. 2010, 4. [CrossRef]

12. Wang, C.; Yang, J.; Myint, S.W.; Wang, Z.; Tong, B. Empirical modeling and spatio-temporal patterns of urban evapotranspiration for the Phoenix metropolitan area, Arizona. Gisci. Remote Sens. 2016, 53, 778-792. [CrossRef]

13. Xing, W.; Wang, W.; Shao, Q.; Yu, Z.; Yang, T.; Fu, J. Periodic fluctuation of reference evapotranspiration during the past five decades: Does Evaporation Paradox really exist in China? Sci. Rep-UK 2016, 6. [CrossRef]

14. Gronlund, C.; O’Neill, M.; Schwartz, J.; Brown, D.; Brines, S. Heat Waves, Impervious Surfaces, and Hospital Admissions among the Elderly in US Cities. Epidemiology 2009, 20S, S145. [CrossRef]

15. Pang, W.T.; Fok, H.S.; Iz, H.B. Mapping impervious surface areas from GIS planimetric data. Surv. Rev. 2008, 40, 108-115. [CrossRef]

16. Zhao, L.; Xia, J.; Xu, C.; Wang, Z.; Sobkowiak, L.; Long, C. Evapotranspiration estimation methods in hydrological models. J. Geogr. Sci. 2013, 23, 359-369. [CrossRef]

17. Zhou, J.; Liu, J.; Yan, D.; Wang, H.; Wang, Z.; Shao, W.; Luan, Y. Dissipation of water in urban area, mechanism and modelling with the consideration of anthropogenic impacts: A case study in Xiamen. J. Hydrol. 2019, 570, 356-365. [CrossRef]

18. Shields, C.; Tague, C. Ecohydrology in semiarid urban ecosystems: Modeling the relationship between connected impervious area and ecosystem productivity. Water Resour. Res. 2015, 51, 302-319. [CrossRef]

19. Wouters, H.; Demuzere, M.; Ridder, K.D.; van Lipzig, N.P.M. The impact of impervious water-storage parametrization on urban climate modelling. Urban Clim. 2015, 11, 24-50. [CrossRef]

20. Nakamichi, T.; Moroizumi, T. Applicability of three complementary relationship models for estimating actual evapotranspiration in urban area. J. Hydrol. Hydromech. 2015, 63, 117-123. [CrossRef]

21. Ramamurthy, P.; Bou-Zeid, E.; Smith, J.A.; Wang, Z.; Baeck, M.L.; Saliendra, N.Z.; Hom, J.L.; Welty, C. Influence of Subfacet Heterogeneity and Material Properties on the Urban Surface Energy Budget. J. Appl. Meteorol. Clim. 2014, 53, 2114-2129. [CrossRef]

22. Saganeiti, L.; Favale, A.; Pilogallo, A.; Scorza, F.; Murgante, B. Assessing Urban Fragmentation at Regional Scale Using Sprinkling Indexes. Sustainability 2018, 10, 3274. [CrossRef] 
23. Meng, C.; Zhang, W. Local and Regional Scale Evaluation of the Integrated Urban Land Model by Comparing with the Common Land Model. Adv. Meteorol. 2019, 2019, 1-11. [CrossRef]

24. Jiang, Y.; Weng, Q. Estimation of hourly and daily evapotranspiration and soil moisture using downscaled LST over various urban surfaces. Gisci. Remote Sens. 2017, 54, 95-117. [CrossRef]

25. Ramamurthy, P.; Bou-Zeid, E. Contribution of impervious surfaces to urban evaporation. Water Resour. Res. 2014, 50, 2889-2902. [CrossRef]

26. Li, Y.; Fan, S.; Li, K.; Zhang, Y.; Dong, L. Microclimate in an urban park and its influencing factors: A case study of Tiantan Park in Beijing, China. Urban. Ecosyst. 2020. [CrossRef]

27. Yu, Z.; Chen, T.; Yang, G.; Sun, R.; Xie, W.; Vejre, H. Quantifying seasonal and diurnal contributions of urban landscapes to heat energy dynamics. Appl. Energ. 2020, 264, 114724. [CrossRef]

28. Mohammadinia, A.; Arulrajah, A.; Horpibulsuk, S.; Chinkulkijniwat, A. Effect of fly ash on properties of crushed brick and reclaimed asphalt in pavement base/subbase applications. J. Hazard. Mater. 2017, 321, 547-556. [CrossRef]

29. Bogawski, P.; Bednorz, E. Comparison and Validation of Selected Evapotranspiration Models for Conditions in Poland (Central Europe). Water Resour. Manag. 2014, 28, 5021-5038. [CrossRef]

30. Mobilia, M.; Longobardi, A. Evaluation of Meteorological Data-Based Models for Potential and Actual Evapotranspiration Losses Using Flux Measurements; Springer International Publishing; Cham, Switzerland, 2020; pp. 3-18.

31. Zhou, J.; Liu, J.; Wang, H.; Wang, Z.; Mei, C. Water dissipation mechanism of residential and office buildings in urban areas. Sci. China Technol. Sci. 2018, 61, 1072-1080. [CrossRef]

32. Zhang, J.; Li, Z. A study on demacation indexes between subhumid and semiarid sectors in China. Adv. Water Sci. 1999, 18, 230-237. [CrossRef]

33. Andersen, C.T.; Foster, I.; Pratt, C.J. The role of urban surfaces (permeable pavements) in regulating drainage and evaporation: Development of a laboratory simulation experiment. Hydrol. Process. 1999, 13, 597-609. [CrossRef] 